\title{
Arterial cannulation site selection: The road less traveled
}

\author{
Alan M. Speir, MD
}

From Cardiac Surgery Services, Inova Heart and Vascular Institute, Falls Church, Va. Disclosures: Author has nothing to disclose with regard to commercial support.

Received for publication Dec 8, 2017; accepted for publication Dec 18, 2017; available ahead of print Feb 1, 2018.

Address for reprints: Alan M. Speir, MD, Cardiac Surgery Services, Inova Heart and Vascular Institute, 3300

Gallows Rd, Falls Church, VA 22042 (E-mail: alan.speir@inova.org).

J Thorac Cardiovasc Surg 2018;155:1961-2

$0022-5223 / \$ 36.00$

Copyright (c) 2018 by The American Association for Thoracic Surgery

https://doi.org/10.1016/j.jtcvs.2017.12.071

Dr Denton A. Cooley, in an article reviewing the history of aortic aneurysm surgery, described aortic disease as "a fundamental problem of mankind."1 His knowledge and expertise have had a huge impact on the surgical approach to aortic disease throughout the last 6 decades. Indeed, the contributions from the 2 institutions with which he was so closely associated during his career, the Texas Heart Institute and Baylor College of Medicine, have served to profoundly influence our techniques and surgical approaches to thoracic aortic aneurysm pathology. The recent manuscript published in this issue of the Journal by Preventza and colleagues, entitled "In Elective Arch Surgery with Circulatory Arrest, Does the Arterial Cannulation Site Really Matter? A Propensity Score Analysis of Right Axillary and Innominate Artery Cannulation," 2 is another example of a significant contribution to the literature from Baylor's exemplary thoracic aortic program.

In their manuscript, Preventza and colleagues describe the cannulation techniques used in Baylor's surgical treatment of elective proximal and total arch cases. Their secondary goal was to assess which technique, innominate or axillary artery cannulation, would facilitate antegrade cerebral perfusion (ACP) during circulatory arrest, thereby making deep hypothermic circulatory arrest unnecessary. Hypothermia has experienced quite a journey over the years extending from the Hippocratic era, where it was described as a treatment for tetanus, ${ }^{3}$ to William Bigelow's Canine and Rhesus monkey experiments on hypothermia to reduce body oxygen requirements to allow exclusion of the heart from circulation, ${ }^{4}$ to Griepp's surface cooling with cardiopulmonary bypass to resect aortic arch aneurysms in 4 patients, ${ }^{5}$ to the current analysis by Preventza and colleagues.

Perhaps the additional contributions in this publication are not only the cannulation techniques, but also the authors' defined and organized approach to such surgical resections. For cardiac surgeons who do not have the huge experience of the authors in such cases, such an operative approach serves as a simplified roadmap for these procedures. Their systematic approach to such

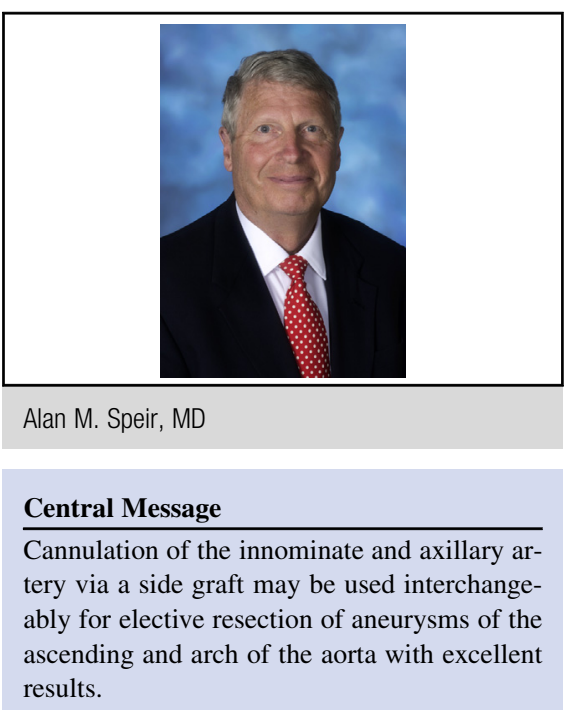

See Article page 1953.

procedures was clearly described: "the targeted nasopharyngeal temperature was approximately $20^{\circ} \mathrm{C}-25^{\circ} \mathrm{C}$ during the period of low flow (10-15 $\mathrm{mL} / \mathrm{kg} / \mathrm{min})$. Transesophageal echocardiography and near-infrared spectroscopy were used by the anesthesia team. For blood pressure monitoring... quite often, the anesthesia team placed right and left radial arterial lines." In addition, and equally important to the cannulation strategy "recently, our default strategy has been to use bilateral ACP regardless of the total ACP time or the complexity of the procedure."

The Baylor path has evolved over the years with cannulation techniques that have moved away from the customary femoral artery approach (now used in only $1.4 \%$ of cases) to axillary or innominate artery cannulation (95\% of cases), with documented impressive clinical outcomes. There is much to be learned and emulated from such a consistent surgical approach.

There are few centers in the world that can draw on such a volume of experience for this type of analysis, and the results speak for themselves. Such outcomes are a demonstration of the surgical advancement learned from constantly seeking to advance our knowledge and gleaned from moving from the known and usual techniques to lesser known but subsequently more enlightened paths at journey's end.

"Two roads diverged in a wood, and I-I took the one less traveled by, And that has made all the difference." 6 


\section{References}

1. Cooley DA. A brief history of aortic aneurysm surgery. Aorta. 2013;1:1-3.

2. Preventza O, Price MD, Spiliotopoulos K, Amarasekara H, Cornwell L, Omer S, et al. In elective arch surgery with circulatory arrest, does the arterial cannulation site really matter? A propensity score analysis of right axillary and innominate artery cannulation. J Thorac Cardiovasc Surg. 2018;155: 1953-60.
3. Adams F. The Genuine Works of Hippocrates. New York: William Wood; 1929.

4. Bigelow WG, McBirnie JE. Further experiences with hypothermia for intracardiac surgery in monkeys and groundhogs. Ann Surg. 1953;137:361-5.

5. Griepp RB, Stinson EB, Hollingsworth JF, Buehler D. Prosthetic replacement of the aortic arch. J Thorac Cardiovasc Surg. 1975;70:1051-63.

6. The Poetry of Robert Frost. Edward Connery Latham. New York: Henry Holt and Company; 1962. 